\title{
Prognostic importance of bile duct invasion in surgical resection with curative intent for hepatocellular carcinoma using PSM analysis
}

\author{
XINWEI YANG $^{1 *}$, ZHIQUAN QIU $^{1 *}$, RONGZHEN RAN ${ }^{1 *}$, LONGJIU CUI $^{1}$, XIANGJI LUO $^{1}$, \\ MENGCHAO WU $^{1}$, WEI-FENG TAN ${ }^{1,2}$ and XIAOQING JIANG ${ }^{1}$ \\ ${ }^{1}$ Department of Biliary Surgery, Eastern Hepatobiliary Surgery Hospital, The Second Military Medical University, \\ Shanghai 200438, P.R. China; ${ }^{2}$ Department of Surgery, University of Pittsburgh School of Medicine, \\ Pittsburgh, PA 15213, USA
}

Received October 22, 2017; Accepted June 28, 2018

DOI: $10.3892 / \mathrm{ol} .2018 .9108$

\begin{abstract}
There is not yet a consensus regarding a difference in prognosis for patients with hepatocellular carcinoma (HCC) with and without bile duct invasion (BDI). The present study aimed to clarify the prognostic importance of BDI on the short and long-term outcome of patients with HCC who underwent surgical resection. The present study evaluated HCC with BDI, including peripheral microscopic biliary invasion and revealed that the prognosis of patients with BDI was poorer compared with those without BDI. It should be noted that peripheral BDI also had a negative impact on the prognosis of patients with HCC. The clinical prognosis assessment revealed that BDI should be considered when assigning a disease stage. BDI, either macroscopic or microscopic, indicated a poor prognosis in patients with $\mathrm{HCC}$ who underwent curative resection, however it was not a surgical contraindication. Macroscopic BDI and hyperbilirubinemia were significantly associated with a dismal prognosis, which should alert surgeons.
\end{abstract}

\section{Introduction}

Jaundice is common in patients with hepatocellular carcinoma (HCC), and it can be detected in $19-40 \%$ of patients at the time of diagnosis (1). It is usually a result of insufficient functioning

Correspondence to: Professor Wei-Feng Tan or Professor Xiaoqing Jiang, Department of Biliary Surgery, Eastern Hepatobiliary Surgery Hospital, The Second Military Medical University, 225 Changhai Road, Shanghai 200438, P.R. China

E-mail: twf1231@163.com

E-mail: yang16jing@163.com

${ }^{*}$ Contributed equally

Key words: hepatocellular carcinoma, bile duct invasion, hyperbilirubinemia, survival, prognosis of the reduced normal hepatic parenchyma resulting from the underlying cirrhosis and tumor replacement (2). The prognosis is extremely poor, and no effective treatment option is available. However, obstructive jaundice secondary to tumor invasion of the major bile ducts or biliary tumor thrombus may benefit from surgical resection (1,3-5). It is important to distinguish hepatic and obstructive jaundice, because the latter is treatable with the potential to prolong patient survival and even in some cases curable. The literature describing experiences with the management of HCC with obstructive jaundice includes mainly case reports and a few reports of large series of patients (5-10). In addition, most previous studies focused only on tumor invasion of the large bile ducts, such as the common bile ducts up to the first branches of the biliary duct, which commonly manifested as obstructive jaundice $(3,11-13)$. However, invasion of the peripheral branches of the bile duct has not been well characterized and is not preoperatively diagnosable due to non-specific clinical manifestations, which usually do not include jaundice.

In this study, the relationships between the clinicopathological factors of HCC and prognosis after curative resection were analyzed retrospectively. The aim was to clarify the prognostic impact of bile duct invasion (BDI), including microscopic invasion of the peripheral branches of the bile duct, on short- and long-term outcomes in HCC patients after curative resection.

\section{Patients and methods}

Patients. A prospectively maintained database that includes HCC patients admitted to Eastern Hepatobiliary Hospital was reviewed. This study enrolled a cohort of 270 patients who were diagnosed with HCC and underwent surgical resection with curative intent performed by a single surgical team between February 2003 and January 2011. Approval from the Institutional Review Board of the Second Military Medical University (Shanghai, China) was obtained prior to data review. Written informed consent was obtained from all patients for surgical treatment and pathological examinations according to the institutional guidelines. 
$\mathrm{R} 0$ or $\mathrm{R} 1$ resections were designated as resection with curative intent (14). Of these 270 cases, macroscopic or microscopic BDI, including biliary tumor thrombus, were identified in 107 cases. Since our surgical team is specialized in the diagnosis and treatment of biliary tract tumors, most HCC patients with preoperative jaundice were admitted to our department. We compared the characteristics of the HCC cases with BDI ( $b^{+}$group, $\left.n=107\right)$ with those of cases without BDI ( $b^{-}$group, $n=163$ ), and we used propensity score matching (PSM) analysis to avoid bias between the $\mathrm{b}^{+}$and $\mathrm{b}^{-}$groups.

Pre-operative assessment. Laboratory data for HCC patients were obtained upon admission before surgery. Possible BDI of HCC was noted when peripheral bile duct dilatation or tumor thrombus was detected by ultrasonography (US) or computed tomography (CT), and the BDI was further assessed by direct cholangiography or magnetic resonance cholangiopancreatography (MRCP) of the obstruction or stenosis of the biliary trees. In patients with BDI who presented with obstructive jaundice, biliary drainage was performed first, and the hepatic functional reserve was evaluated after the serum bilirubin level was lower than $5 \mathrm{mg} / \mathrm{dl}$. Liver resection was performed next.

Operative procedures. The extent of hepatectomy was selected based on the location and size of the tumor, liver function, and volume of liver parenchyma. Hepatectomies included partial resection, subsegmentectomy, segmentectomy, lobectomy, and extended lobectomy, and they were performed with the intent to remove the entire tumor and the concomitant bile ducts. When the tumor invasion extended to the extrahepatic bile duct or contralateral hepatic duct, the resection was accompanied by removal of extrahepatic bile ducts or by cholangiotomy.

Pathological assessment. Resected specimens were evaluated macroscopically and microscopically according to TNM stage (UICC 7th edition) (15). Two pathologists independently reviewed all sections and reached a consensus on the pathologic features of all cases. Macroscopic BDI was defined as tumor thrombus in the common hepatic ducts or the first to second branches of the bile duct. Microscopic BDI was defined as tumor thrombus in the third order or lower peripheral branches of the bile duct. Patients with these two types of BDI were included in the BDI $\left(\mathrm{b}^{+}\right)$group. Survival was measured from the time of hepatic resection, and death marked the endpoint. Outcomes in this cohort were reviewed in January 2016.

Statistical analysis. The two groups were compared using Mann-Whitney U test for non-parametric data. The Chi-square test was used for categorical data. Survival curves were estimated with the Kaplan-Meier method and compared by the log-rank test. Cox regression analysis was carried out to determine which factor was the best prognostic determinant. $\mathrm{P}<0.05$ was considered to indicate a statistically significant difference. Calculations were done using SPSS version 17.0 for Windows (SPSS, Inc., Chicago, IL, USA). After comparing the demographic data between the two groups, we performed PSM analysis using logistic regression to create a propensity score for patients in the $\mathrm{b}^{+}$and $\mathrm{b}^{-}$groups. One-to-one matching between the two groups was done using the nearest-neighbor matching method. The PH assumption was checked. The caliper value was 0.2 .

\section{Results}

Demographic data. The clinical features of the $\mathrm{b}^{+}$and $\mathrm{b}^{-}$ groups are presented in Table I. A typicl clinical case of HCC with BDI was described in Fig. 1. No differences in sex, age, serum AFP level, prothrombin time (PT), and the percentages of viral hepatitis and cirrhosis were observed between the $\mathrm{b}^{+}$and $\mathrm{b}^{-}$groups. The levels of serum total bilirubin (sTBIL; $\mathrm{P}<0.001$ ), serum albumin (sALB; $\mathrm{P}<0.001$ ), and serum alanine transaminase (sALT; $\mathrm{P}<0.001)$ as well as tumor size $(\mathrm{P}=0.012)$ and presence of multiple tumor lesions $(\mathrm{P}=0.031)$ were significantly higher in the $\mathrm{b}^{+}$group than in the $\mathrm{b}^{-}$group. In addition, BDI may not always cause jaundice. There were 42 cases in $b^{+}$ group who did not present with jaundice.

Postoperative complications and mortality. Two cases of in-hospital deaths occurred in each group, and these patients died of hepatic failure within 1 month after surgery. Thirteen of the 107 HCC patients in the $b^{+}$group $(13 / 107,12.1 \%)$ developed postoperative complications. These cases included 5 patients with pleural effusions, 3 with hemobilia, 1 with a biliary tract infection, 1 with bile leakage, 1 with upper gastrointestinal ulcer bleeding, 1 with a thoracic epidural hematoma, and 2 with infection at the incision site. During the same period, only five patients in the $b^{-}$group $(5 / 163,3.1 \%)$ had postoperative complications, including 4 cases of pleural effusion and 1 of incision site infection (Table II).

Comparison of survival between the $b^{+}$group and $b^{-}$group. The median disease-free survival (DFS) times in the $b^{+}$and $\mathrm{b}^{-}$groups were 8 and 33 months, respectively. The cumulative 1-, 3-, and 5-year DFS rates in the $\mathrm{b}^{+}$group (37.2, 11.5 , and $0 \%$, respectively) were significantly worse than those in the $b^{-}$group $(59.4,47.9$, and $24.5 \%$, respectively; $\mathrm{P}<0.001)$. The median overall survival (OS) times were 16.6 and 84.0 months in the $\mathrm{b}^{+}$and $\mathrm{b}^{-}$groups, respectively. The cumulative 1-, 3-, and 5-year survival rates in the $\mathrm{b}^{+}$group $(60.5,20.1$, and $12.0 \%$, respectively) were significantly poorer than those in the $\mathrm{b}^{-}$group $(84.9,69.9$, and $57.6 \%$, respectively; $\mathrm{P}<0.001$, Fig. 2).

Risk factors for reduced DFS. Univariate analysis revealed that age, BDI, portal vein tumor thrombosis (PVTT), sAFP level, viral hepatitis, cirrhosis, tumor size, multiple tumor lesions, sTBIL level, and SALB level significantly affected DFS (Table III). Prognostic factors for poor DFS were further identified by multivariate analysis and included $\mathrm{BDI}(\mathrm{P}<0.001)$, PVTT $(\mathrm{P}<0.001)$, high sAFP level $\geq 20 \mathrm{ng} / \mathrm{ml}(\mathrm{P}=0.001)$, and age $\geq 60$ years $(P=0.037$; Table IV). However, tumor size and multiple tumor lesions were not an independently significant factor by multivariate analysis.

Risk factors for reduced OS. Univariate analysis revealed that sex, BDI, PVTT, AFP level, multiple tumor lesions, tumor differentiation, sALB level, sTBIL level, and sALT level significantly affected OS (Table V). Multivariate analysis showed that sex $(\mathrm{P}=0.034)$, BDI $(\mathrm{P}=0.001)$, PVTT $(\mathrm{P}=0.007)$, 
Table I. Demographic data of $b^{+}$group and $b^{-}$group.

\begin{tabular}{|c|c|c|c|}
\hline Variables & $\begin{array}{l}\mathrm{b}^{+} \text {group } \\
(\mathrm{n}=107)\end{array}$ & $\begin{array}{l}b^{-} \text {group } \\
(n=163)\end{array}$ & P-value \\
\hline Male sex & 88 & 140 & 0.419 \\
\hline Mean age (years) & $50.6 \pm 10.5$ & $49.5 \pm 10.6$ & 0.388 \\
\hline TBIL, mg/dl (range) & $\begin{array}{c}3.57 \\
(0.50-28.01)\end{array}$ & $\begin{array}{c}0.84 \\
(0.33-2.82)\end{array}$ & $<0.001$ \\
\hline $\operatorname{ALB}(\mathrm{g} / \mathrm{l})$ & $39.4 \pm 4.3$ & $42.5 \pm 3.9$ & $<0.001$ \\
\hline ALT grade (U/l) & & & $<0.001$ \\
\hline$<40$ & 17 & 82 & \\
\hline$\geq 40$ & 90 & 81 & \\
\hline AFP grade (ng/ml) & & & 0.163 \\
\hline$<20$ & 30 & 59 & \\
\hline$\geq 20$ & 77 & 104 & \\
\hline PT grade (second) & & & 0.753 \\
\hline$<14$ & 98 & 151 & \\
\hline$\geq 14$ & 9 & 12 & \\
\hline Tumor size (cm) & & & 0.012 \\
\hline$<5$ & 49 & 50 & \\
\hline$\geq 5$ & 58 & 113 & \\
\hline Multiple tumor lesions & & & 0.031 \\
\hline Yes & 22 & 18 & \\
\hline No & 85 & 145 & \\
\hline PVTT & & & 0.747 \\
\hline Yes & 13 & 22 & \\
\hline No & 94 & 141 & \\
\hline Presence of hepatitis & & & 0.084 \\
\hline Yes & 105 & 152 & \\
\hline No & 2 & 11 & \\
\hline Presence of cirrhosis & & & 0.508 \\
\hline Yes & 58 & 95 & \\
\hline No & 49 & 68 & \\
\hline UICC 7th edition & & & 0.796 \\
\hline I & 16 & 23 & \\
\hline II & 24 & 40 & \\
\hline III & 62 & 92 & \\
\hline IV & 5 & 8 & \\
\hline
\end{tabular}

Male sex, mean age (years), TBIL (mg/dl) and ALB (g/l) were compared using Mann-Whitney U test. ALT grade (U/l), AFP grade $(\mathrm{ng} / \mathrm{ml})$, PT grade (second), tumor size $(\mathrm{cm})$, multiple tumor lesions, PVTT, presence of hepatitis, presence of cirrhosis and UICC 7th edition were compared using Chi-square test. TBIL, total bilirubin; ALB, albumin; ALT, alanine transaminase; PT, prothrombin time; AFP, alpha-fetoprotein.

$\mathrm{sAFP} \geq 20 \mathrm{ng} / \mathrm{ml}(\mathrm{P}=0.014)$, AALB $(\mathrm{P}=0.005)$, and high sTBIL $\geq 2 \mathrm{mg} / \mathrm{dl}(\mathrm{P}=0.008)$ were independent risk factors for reduced OS (Table VI).

Survival analysis in 36 pairs of patients from the two groups matched with PSM. Because the demographic data were diverse between the $b^{+}$and $b^{-}$patients, we opted to match 36 pairs of cases for all risk factors except BDI through PSM analysis and
Table II. Postoperative complications in $\mathrm{b}^{+}$group $(\mathrm{n}=107)$ and $b^{-}$group $(n=163)$.

\begin{tabular}{lccc}
\hline Complications & $\mathrm{b}^{+}(\mathrm{n}=107)$ & $\mathrm{b}^{-}(\mathrm{n}=163)$ & P-value \\
\hline Pleural effusions & 5 & 4 & \\
Hemobilia & 3 & 0 & \\
Biliary tract infections & 1 & 0 & \\
Bile leakage & 1 & 0 & \\
Upper gastrointestinal & 1 & 0 & \\
bleeding & & & \\
Thoracic epidural & 1 & 0 & 0.003 \\
hematoma & & & \\
Incision infection & 2 & 1 & \\
Total & 13 & 5 & \\
\hline
\end{tabular}

to compare them directly to determine whether BDI was an independent factor for poor prognosis. The overall balance between the two matched groups was excellent $(\mathrm{P}=1.00)$, and no unbalanced covariates ( $\mid \mathrm{dl}>25$ ) were found. Despite matching for sex, age, PVTT, tumor size, multiple tumor lesions, sALT, sPT, sAFP, sALB, and sTBIL levels, the $\mathrm{b}^{-}$and $\mathrm{b}^{+}$patients showed significant differences in DFS and OS.

The cumulative 1-, 3-, and 5-year DFS rates in the $\mathrm{b}^{+}$group (39.2, 16.6, and $0 \%$, respectively) were significantly worse than those in the $b^{-}$group $(64.3,40.7$, and $25.4 \%$, respectively; $\mathrm{P}=0.006)$. The cumulative 1-, 3-, and 5-year survival rates in the $b^{+}$group $(75.6,34.0$, and $25.5 \%$, respectively) were significantly poor than those in the $\mathrm{b}^{-}$group $(87.9,70.2$, and $55.3 \%$, respectively; $\mathrm{P}=0.024$, Fig. 3 ). Therefore, BDI was verified as a critical prognostic factor associated with both poor DFS and OS in this cohort.

Differences in DFS and OS between HCC patients with microscopic and macroscopic BDI. Postoperative DFS was similar between the groups of HCC patients with microscopic BDI $(n=10)$ and macroscopic BDI $(n=97 ; P=0.401$, Fig. 4), but the DFS rates for both these groups were poorer than that in the $\mathrm{b}^{-}$group $(\mathrm{P}=0.048$ and $\mathrm{P}<0.001$, respectively). Postoperative OS in HCC patients with macroscopic BDI was significantly worse than that in those with microscopic BDI $(\mathrm{P}=0.008)$ and that in the $\mathrm{b}^{-}$group $(\mathrm{P}<0.001)$. Postoperative OS did not differ significantly between HCC patients with microscopic BDI and those in the $\mathrm{b}^{-\mathrm{v}}$ group ( $\mathrm{P}=0.412$, Fig. 4).

Differences in postoperative DFS and OS between HCC patients with BDI and those with PVTT. There were no significant differences in the postoperative DFS and OS between HCC with single BDI $(n=93)$ and those with single PVTT $(\mathrm{n}=19 ; \mathrm{P}>0.05$, Fig. 5).

Tumor recurrence in 107 HCC patients with BDI ( $b^{+}$group). Seventy-five patients in the $\mathrm{b}^{+}$group experienced $\mathrm{HCC}$ recurrence during follow-up. Most cases of recurrence occurred in the liver, including 58 cases $(58 / 75,77.3 \%)$ in the remnant liver and 53 cases $(53 / 75,70.7 \%)$ in the bile ducts. The other sites included lung in 10 cases $(13.3 \%)$, bone in 3 cases $(4 \%)$, 

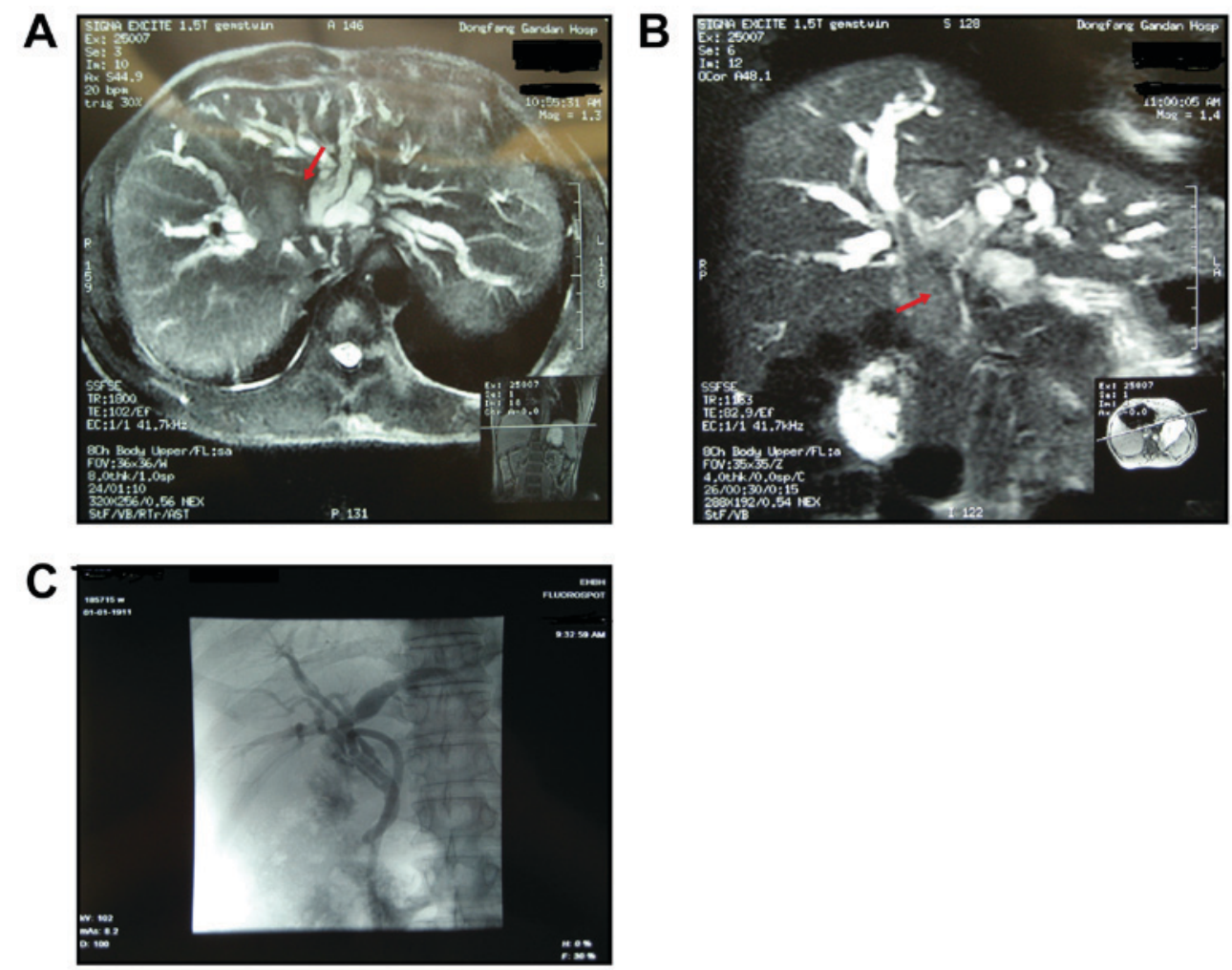

Figure 1. Typical imaging features of hepatocellular carcinoma with bile duct invasion. (A) MRI indicates a tumor mass in the right of the liver. (B) Preoperative magnetic resonance cholangiopancreatography reveals a biliary tumor thrombus extending superficially from an intrahepatic to an extra hepatic bile duct. The red arrows indicate a biliary tumor thrombus. (C) T tube angiography was performed 2 months following surgery and revealed normal results without recurrence.
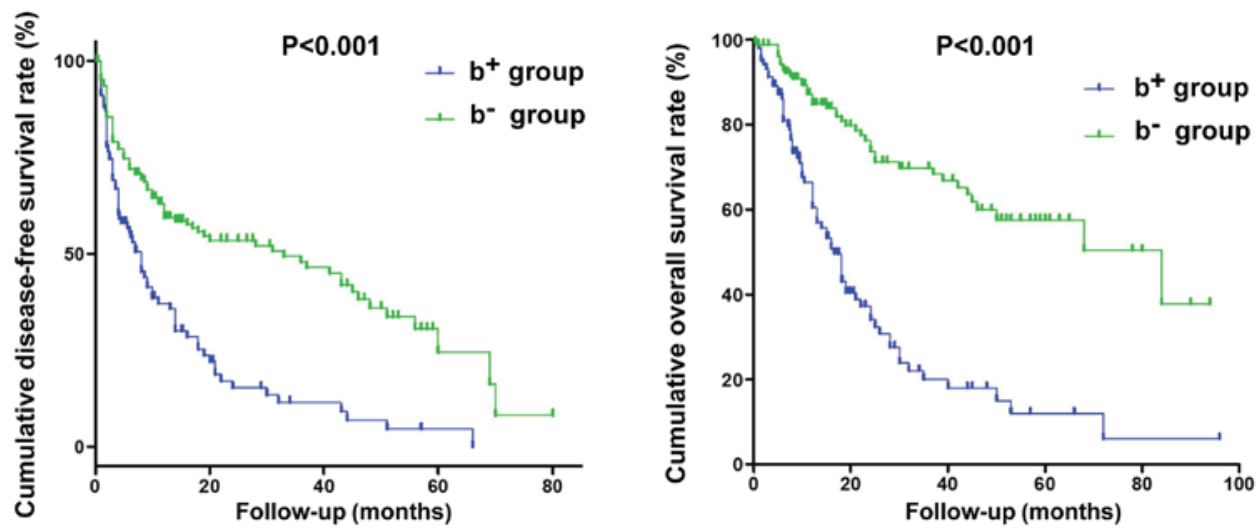

Figure 2. Postoperative disease-free survival and overall survival curves for the $b^{+}$and $b^{-}$groups. The cumulative 1-, 3-, and 5-year survival rates in the $b^{+}$group were significantly poorer than those in the $b^{-}$group.

abdomen in 2 cases $(2.7 \%)$, and brain in 2 cases $(2.7 \%)$, and 7 cases $(9.3 \%)$ experienced retroperitoneal metastasis.

\section{Discussion}

We retrospectively analyzed risk factors for poor prognosis in a cohort of $270 \mathrm{HCC}$ patients who underwent curative resection performed by our single surgical team. Of the 270 patients, 107 had BDI. This study is one of the largest investigations of the effects of BDI that has been published. We found BDI was constistently identified as a risk factor for reduced survival together with others variables. Furthermore, we directly compared the outcomes associated with BDI after matching for all other risk factors and verified that BDI was the determining risk factor for poor prognosis of HCC by comparing DFS and OS after curative hepatectomy. Our findings provide two implications for the clinical management of HCC patients. One is that jaundice in HCC could be associated with BDI and is surgically treatable $(16,17)$. Jaundice is present in $19-40 \%$ of patients with HCC at the time of diagnosis and is caused by diffuse tumor infiltration of the liver parenchyma, progressive liver failure, hepatic hilar invasion, severe cirrhosis, or a combination of these factors (1-4). There is no good treatment option for jaundice resulting from insufficient liver function. On the other hand, 
Table III. Univariate analysis of 13 variables associated with DFS in patients with HCC who underwent surgical resection with curative intent $(n=270)$.

\begin{tabular}{|c|c|c|c|c|}
\hline Variables & Cut off values & Total & Disease-free survival time (months) & P-value \\
\hline \multirow[t]{3}{*}{ Sex } & & & & 0.143 \\
\hline & Male & 228 & $14.0 \pm 2.5$ & \\
\hline & Female & 42 & $6.0 \pm 2.8$ & \\
\hline \multirow[t]{3}{*}{ Age (years) } & & & & 0.006 \\
\hline & $<60$ & 222 & $11.0 \pm 2.2$ & \\
\hline & $\geq 60$ & 48 & $48.0 \pm 21.8$ & \\
\hline \multirow[t]{3}{*}{ Bile duct invasion } & & & & $<0.001$ \\
\hline & Yes & 107 & $8.0 \pm 1.2$ & \\
\hline & No & 163 & $33.0 \pm 9.9$ & \\
\hline \multirow[t]{3}{*}{ PVTT } & & & & $<0.001$ \\
\hline & Yes & 35 & $5.0 \pm 1.4$ & \\
\hline & No & 235 & $18.0 \pm 2.6$ & \\
\hline \multirow[t]{3}{*}{ Presence of hepatitis } & & & & 0.003 \\
\hline & Yes & 257 & $12.0 \pm 2.4$ & \\
\hline & No & 13 & $60.2 \pm 9.8$ & \\
\hline \multirow[t]{3}{*}{ Presence of cirrhosis } & & & & 0.052 \\
\hline & Yes & 153 & $18.0 \pm 3.4$ & \\
\hline & No & 117 & $11.0 \pm 1.9$ & \\
\hline \multirow[t]{3}{*}{ Tumor size (cm) } & & & & 0.021 \\
\hline & $<5$ & 99 & $21.0 \pm 2.0$ & \\
\hline & $\geq 5$ & 171 & $9.0 \pm 1.6$ & \\
\hline \multirow[t]{3}{*}{ Multiple tumor lesions } & & & & 0.010 \\
\hline & Yes & 40 & $4.2 \pm 1.9$ & \\
\hline & No & 230 & $17.0 \pm 2.8$ & \\
\hline \multirow[t]{3}{*}{$\mathrm{AFP}(\mathrm{ng} / \mathrm{ml})$} & & & & $<0.001$ \\
\hline & $<20$ & 89 & $43.0 \pm 7.4$ & \\
\hline & $\geq 20$ & 181 & $9.0 \pm 1.4$ & \\
\hline \multirow[t]{3}{*}{ PT (sec) } & & & & 0.328 \\
\hline & $<14$ & 249 & $14.0 \pm 2.6$ & \\
\hline & $\geq 14$ & 21 & $10.0 \pm 3.6$ & \\
\hline \multirow[t]{3}{*}{ TBIL (mg/dl) } & & & & 0.001 \\
\hline & $<2$ & 203 & $18.0 \pm 5.7$ & \\
\hline & $\geq 2$ & 67 & $8.0 \pm 2.0$ & \\
\hline \multirow[t]{3}{*}{$\operatorname{ALB}(g / l)$} & & & & 0.001 \\
\hline & $<35$ & 22 & $3.6 \pm 3.2$ & \\
\hline & $\geq 35$ & 248 & $16.0 \pm 2.5$ & \\
\hline \multirow[t]{3}{*}{ ALT (U/l) } & & & & 0.039 \\
\hline & $<40$ & 99 & $18.0 \pm 11.9$ & \\
\hline & $\geq 40$ & 171 & $12.0 \pm 2.4$ & \\
\hline
\end{tabular}

DFS, disease-free survival ; HCC, hepatocellular carcinoma; TBIL, total bilirubin; PVTT, portal vein tumor thrombosis; ALB, albumin; ALT, alanine transaminase; PT, prothrombin time; AFP, $\alpha$-fetoprotein.

obstructive jaundice resulting from BDI of a major bile duct is an uncommon, but treatable, cause of jaundice in HCC patients. It is important to recognize this cause and devise an appropriate treatment that will benefit patients, including prolonging their survival, and even occasionally provide a cure $(1,3-5,18)$.
In our study, the typical clinical features of BDI in HCC are repeated episodes of cholangitis and fluctuating jaundice, and it is often misdiagnosed as cholangiocarcinoma. In addition, BDI may not always cause jaundice. There were 10 cases of HCC with microscopic BDI and 32 cases with macroscopic 
Table IV. Multivariate analysis for DFS in patients with HCC who underwent surgical resection with curative intent (n=270).

\begin{tabular}{lccccc}
\hline Variable & Regression coefficient & Standard error & P-value & Relative risk & $95 \%$ CI \\
\hline Age & -0.542 & 0.260 & 0.037 & 0.582 & $0.350-0.968$ \\
Bile duct invasion & 0.828 & 0.163 & $<0.001$ & 2.290 & $1.664-3.150$ \\
PVTT & 0.948 & 0.217 & $<0.001$ & 2.580 & $1.687-3.946$ \\
AFP & 0.665 & 0.193 & 0.001 & 1.944 & $1.332-2.838$ \\
\hline
\end{tabular}

DFS, disease-free survival; HCC, hepatocellular carcinoma; CI, confidence interval; PVTT, portal vein tumor thrombosis; AFP, $\alpha$-fetoprotein.

BDI in our cohort who did not present with jaundice. Strictly speaking, these two conditions should be distinguished in further studies.

Only a few reports with a small number of cases of HCC with BDI have been published $(3,5-9)$. Surgical resection has been considered the preferred treatment for $\mathrm{HCC}$ with BDI; however, there has been no consensus regarding the differences in prognosis of HCC with and without BDI. In the present study, we found that macroscopic BDI and hyperbilirubinemia were significantly associated with an adverse prognosis in HCC patients. Thus, the second implication of our findings is that hepatologists should be informed of the detection of BDI, because BDI was an indicator of poor prognosis in HCC patients who underwent curative resection in this study.

Previous studies $(3,11-13)$ focused on tumor invasion of the large bile ducts, such as the common bile ducts up to the first branches of the hepatic duct. HCC invasion of a peripheral bile duct has not been well studied. In the present study, we evaluated HCC with BDI, including peripheral microscopic biliary invasion, and found that it was also associated with poor outcomes. Thus, even peripheral BDI has a negative impact on DFS in HCC patients. A further analysis showed that macroscopic BDI was significantly associated with poor prognosis, whereas microscopic BDI was not. However, macroscopic BDI was dominantly responsible for obstructing jaundice. In clinical assessment of prognosis, macroscopic BDI should be considered in the assignment of clinical stage.

BDI indicates a high degree of HCC invasiveness. In this study, the DFS and OS of the $\mathrm{b}^{+}$group were significantly poorer than those of the $b^{-}$group. The incidence of postoperative complications in patients with HCC complicated with biliary tumor invasion is higher, which may be related to the higher degree of malignancy and stronger invasive ability. To understand the cancer biology responsible for this observation, we noted that both the size and numbers of tumors differed significantly between the two groups $(\mathrm{P}=0.012$ and $\mathrm{P}=0.031$, respectively). The $\mathrm{b}^{+}$group was characterized by a high proportion of patients with multiple tumors and a small primary lesion $<5 \mathrm{~cm}$ in diameter, and these two factors were also found to be closely related to postoperative prognosis in HCC. In addition, a considerable number of patients in the $\mathrm{b}^{+}$group presented with jaundice upon admission due to bile duct tumor thrombosis. A possible link between the presence of multiple tumors and BDI suggests a quick spreading and invasive nature of the $\mathrm{HCC}$ in this group and the number of tumors was more ominous than the size of the tumors.
In our view, the biology of BDI is similar to that of vascular invasion, especially PVTT, which is often present and recognized as a prognostic factor in HCC patients (19-22). The median survival time among HCC patients with PVTT has been reported to be 2.7-4.0 months without intervention (19). Although an increasing variety of therapeutic options that offer survival benefits are available for HCC patients with PVTT (20), the long-term prognosis remains poor due to the extensive spreading of the tumor throughout the liver and the increased portal blood pressure that results in variceal ruptures, ascites, hepatic encephalopathy, liver failure, and death $(21,22)$. As expected, PVTT was found to be an independent negative risk factor for both DFS and OS $(\mathrm{P}<0.001$ and $\mathrm{P}=0.005$, respectively) in this study. These findings suggest that HCC with BDI shares a similar degree of invasiveness as HCC with PVTT. Once a tumor thrombus forms in the remnant bile ducts and causes hyperbilirubinemia, few treatment options are available. On the contrary, multiple adjuvant therapies can be used to treat the relapsed PVTT.

TBIL level is an important factor in assessing the prognosis of HCC. In this study, the preoperative serum TBIL level was found to be a significant independent prognostic factor for OS $(\mathrm{P}=0.001)$. Hyperbilirubinemia is an important clinical feature of HCC with BDI. We have reported that the preoperative BIL level is a significant prognostic factor for DFS and OS after liver transplantation ( $\mathrm{P}=0.046$ and $\mathrm{P}=0.002$, respectively) (23). In the present study, we also identified that hyperbilirubinemia was an indicator of advanced $\mathrm{HCC}$ with poor prognosis.

Liver surgery in these patients may not be safe because of the hepatic and systemic changes caused by hyperbilirubinemia and the resultant cholangitis $(24,25)$. Thus, preoperative biliary drainage (PBD) is essential for safe hepatectomy. PBD can increase cholestatic liver tolerance to ischemia and reduce blood loss $(26,27)$. The clinical success rate of PBD (endoscopic or percutaneous) ranges from $48.4-100 \%$ in the literature $(28,29)$. Percutaneous transhepatic cholangial drainage (PTCD) is more commonly applied at our center as both the risks associated with PTCD and the economic burden are lower. Drainage of the remnant liver is mandatory, and the drainage of obstructed segments is not necessary unless cholangitis is present. When BDI is located in the secondary or even a more proximal part of the biliary tree, PTBD will be easier than PBD. Thus, we do not necessarily view hyperbilirubinemia as a surgical contraindication. In our experience, TBIL levels were decreased in several patients with hyperbilirubinemia after PBD, leading to the increased survival rates following resection. In our 
Table V. Univariate analysis of 13 variables associated with OS in patients with HCC who underwent surgical resection with curative intent $(n=270)$.

\begin{tabular}{|c|c|c|c|c|}
\hline Variables & Cut off value & Total & Overall survival time (months) & P-value \\
\hline \multirow[t]{3}{*}{ Sex } & & & & 0.035 \\
\hline & Male & 228 & $37.0 \pm 7.0$ & \\
\hline & Female & 42 & $21.0 \pm 3.3$ & \\
\hline \multirow[t]{3}{*}{ Age (years) } & & & & 0.345 \\
\hline & $<60$ & 222 & $44.5 \pm 3.2$ & \\
\hline & $\geq 60$ & 48 & $52.9 \pm 6.7$ & \\
\hline \multirow[t]{3}{*}{ Bile duct invasion } & & & & $<0.001$ \\
\hline & Yes & 107 & $16.6 \pm 1.7$ & \\
\hline & No & 163 & $84.0 \pm 21.6$ & \\
\hline \multirow[t]{3}{*}{ PVTT } & & & & 0.006 \\
\hline & Yes & 35 & $18.0 \pm 1.5$ & \\
\hline & No & 235 & $40.0 \pm 6.7$ & \\
\hline \multirow[t]{3}{*}{ Presence of hepatitis } & & & & 0.041 \\
\hline & Yes & 257 & $44.9 \pm 3.1$ & \\
\hline & No & 13 & $66.5 \pm 8.2$ & \\
\hline \multirow[t]{3}{*}{ Presence of cirrhosis } & & & & 0.534 \\
\hline & Yes & 153 & $37.0 \pm 8.6$ & \\
\hline & No & 117 & $28.0 \pm 6.9$ & \\
\hline \multirow[t]{3}{*}{ Tumor size $(\mathrm{cm})$} & & & & 0.184 \\
\hline & $<5$ & 99 & $42.0 \pm 8.3$ & \\
\hline & $\geq 5$ & 171 & $25.0 \pm 7.9$ & \\
\hline \multirow[t]{3}{*}{ Multiple tumor lesions } & & & & 0.029 \\
\hline & Yes & 40 & $17.0 \pm 1.9$ & \\
\hline & No & 230 & $37.0 \pm 6.9$ & \\
\hline \multirow[t]{3}{*}{$\mathrm{AFP}(\mathrm{ng} / \mathrm{ml})$} & & & & $<0.001$ \\
\hline & $<20$ & 89 & $68.0 \pm 21.0$ & \\
\hline & $\geq 20$ & 181 & $24.0 \pm 4.1$ & \\
\hline \multirow[t]{3}{*}{ PT (sec) } & & & & 0.078 \\
\hline & $<14$ & 249 & $39.0 \pm 6.9$ & \\
\hline & $\geq 14$ & 21 & $25.0 \pm 4.6$ & \\
\hline \multirow[t]{3}{*}{ TBIL (mg/dl) } & & & & $<0.001$ \\
\hline & $<2$ & 203 & $50.0 \pm 10.9$ & \\
\hline & $\geq 2$ & 67 & $13.0 \pm 1.7$ & \\
\hline \multirow[t]{3}{*}{$\operatorname{ALB}(g / l)$} & & & & $<0.001$ \\
\hline & $<35$ & 22 & $8.0 \pm 3.3$ & \\
\hline & $\geq 35$ & 248 & $39.0 \pm 6.5$ & \\
\hline \multirow[t]{3}{*}{$\operatorname{ALT}(\mathrm{U} / \mathrm{l})$} & & & & 0.002 \\
\hline & $<40$ & 99 & $61.7 \pm 5.4$ & \\
\hline & $\geq 40$ & 171 & $38.2 \pm 3.2$ & \\
\hline
\end{tabular}

TBIL, total bilirubin; PVTT, portal vein tumor thrombosis; ALB, albumin; ALT, alanine transaminase; PT, prothrombin time; AFP, $\alpha$-fetoprotein.

experience, a routine PBD via PTCD and oral bilirubin for several days before operation will mitigate hyperbilirubinemia in most cases of obstructive jaundice.

Are bile duct resection and bilioenteric anastomosis required for managing HCC with BDI? Another controversy is whether extrahepatic bile duct resection is necessary in the treatment of HCC with BDI. In the present study, there seemed to be no correlation between bile duct resection and prognosis or HCC recurrence. Noda et al (30) reported that bile duct resection might be avoided in favor or non-operative treatments such as percutaneous ethanol injection therapy (PEIT), ablation, and 
Table VI. Multivariate analysis for OS in HCC patients who underwent surgical resection with curative intent $(\mathrm{n}=270)$.

\begin{tabular}{|c|c|c|c|c|c|}
\hline Variable & Regression coefficient & Standard error & P-value & Relative risk & $95 \% \mathrm{CI}$ \\
\hline Sex & -0.536 & 0.253 & 0.034 & 0.585 & $0.357-0.960$ \\
\hline Bile duct invasion & 0.856 & 0.251 & 0.001 & 2.353 & $1.437-3.852$ \\
\hline PVTT & 0.688 & 0.257 & 0.007 & 1.990 & $1.203-3.293$ \\
\hline AFP & 0.580 & 0.236 & 0.014 & 1.785 & $1.125-2.852$ \\
\hline ALB & -0.813 & 0.292 & 0.005 & 0.444 & $0.250-0.786$ \\
\hline TBIL & 0.695 & 0.263 & 0.008 & 2.004 & $1.196-3.359$ \\
\hline
\end{tabular}

OS, overall survival; HCC, hepatocellular carcinoma; CI, confidence interval; PVTT, portal vein tumor thrombosis; AFP, $\alpha$-fetoprotein; TBIL, total bilirubin; ALB, albumin.
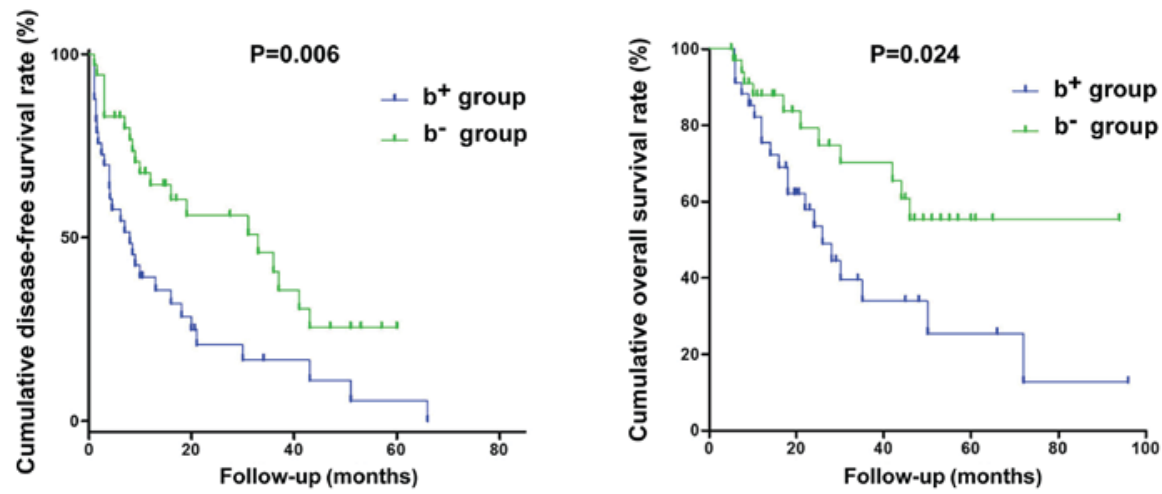

Figure 3. Postoperative OS and DFS curves for 36 pairs of patients matched using PSM analysis. BDI was verified as a critical prognostic factor associated with both poor DFS and OS in this cohort. DFS, disease-free survival; OS, overall survival; BDI, bile duct invasion; PSM, propensity score matching.
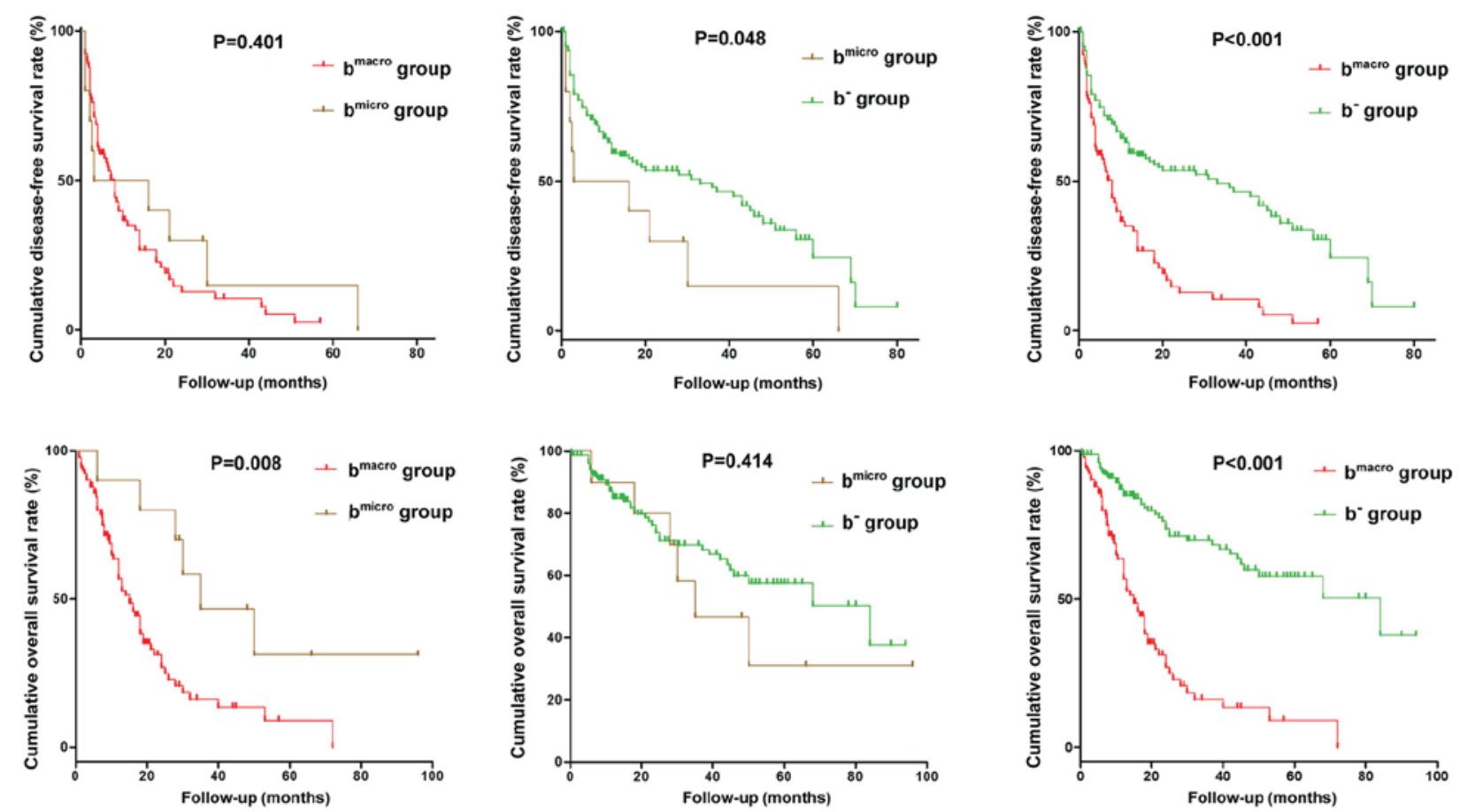

Figure 4. Postoperative disease-free survival and OS curves for hepatocellular carcinoma patients with microscopic or macroscopic BDI. Postoperative OS in HCC patients with macroscopic BDI was significantly worse than that in those with microscopic BDI and that in the $\mathrm{b}^{-}$group. BDI, bile duct invasion; OS, overall survival.

transcatheter arterial chemoembolization (TACE), based on the potential for serious complications such as liver abscess after bile duct resection and bilioenteric anastomosis $(31,32)$. Moreover, because postoperative recurrence after resection of 

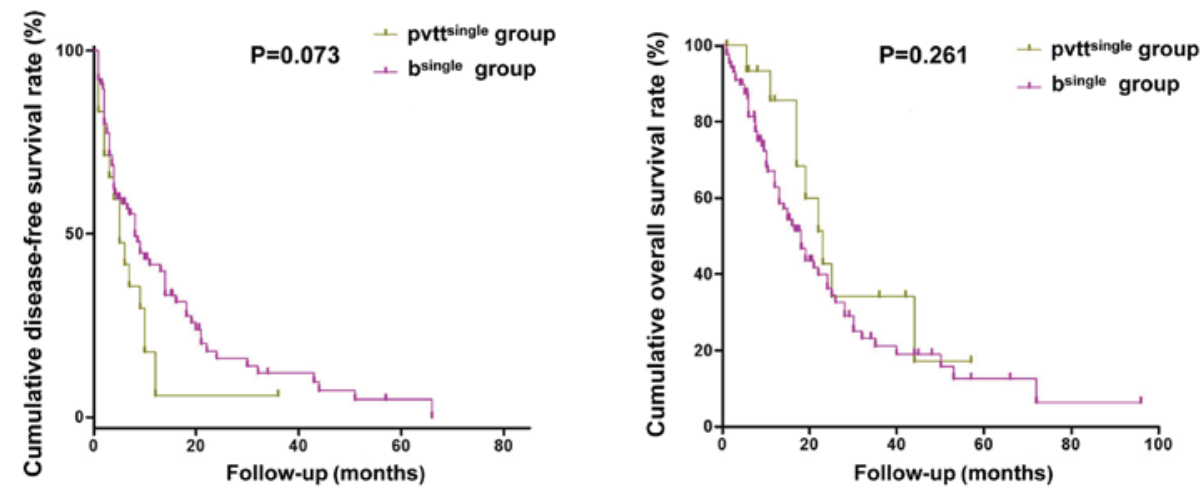

Figure 5. Postoperative DFS and OS curves for hepatocellular carcinoma patients with single BDI or single portal vein tumor thrombosis. There were no significant differences in the postoperative DFS and OS between two groups. DFS, disease-free survival; OS, overall survival; BDI, bile duct invasion.

HCC with BDI often occurs in the remanent liver, bile duct resection and bilioenteric anastomosis should be avoided whenever possible to avoid limiting later treatment options.

Recently, Yamamoto et al (25) reported a bile duct-preserving surgery termed the 'peeling off technique' for HCC with BDI, which is similar to our surgical approach. Preservation of the bile duct is important for two reasons. First, bile duct tumor thrombus demonstrates extensive growth potential and does not usually adhere to the bile duct wall. Second, treatments for recurrence, such as TACE or radiofrequency ablation (RFA), are restricted after resection of the extrahepatic bile duct because liver abscess formation after TACE and RFA is relatively common when an underlying bilioenteric anastomosis is present $(33,34)$. In the current study, only three patients with BDI underwent extrahepatic bile duct resection and bilioenteric anastomosis.

This study has several limitations. Despite the large number of patients included in the present study, the enrolled patients represented a highly selected cohort, as only a fraction of the total number of $\mathrm{HCC}$ patients diagnosed during the study period had BDI. Additional investigations with a large patient population carried out in multiple centers are needed to verify the main findings. In addition, the proposed cancer biology, i.e., the high degree of invasiveness of HCC with BDI, should be further investigated in a laboratory setting.

In conclusion, BDI, including macroscopic and microscopic BDI, reflects a high degree of HCC aggressiveness but does not represent a surgical contraindication. Macroscopic BDI and hyperbilirubinemia were indicative of poor prognosis for HCC patients, which should alert surgeons. Extrahepatic bile duct resection and bilioenteric anastomosis are not required for managing $\mathrm{HCC}$ patients with BDI.

\section{Acknowledgements}

The authors would like to thank Dr Du Jing (The Second Military Medical University) for their assistance in the preparation of this manuscript.

\section{Funding}

The present study was supported by grants from the Natural Science Foundation of Shanghai (grant nos. 20124Y154 and 20164Y0109).

\section{Availability of data and materials}

The datasets used and analyzed during the current study are available from the corresponding author on reasonable request.

\section{Authors' contributions}

$\mathrm{XY}, \mathrm{ZQ}$ and RR performed the majority of the research and collected all the clinicopathological data. XY wrote the manuscript. LC, XL and RR assisted with the analysis and edited the manuscript. W-FT, XJ and MW designed the study. All authors read and approved the final manuscript.

\section{Ethics approval and consent to participate}

The present study was approved by the Ethics Committee of the Second Military Medical University. Written informed consent was obtained from all patients prior to surgical treatment, pathological examinations and further analysis.

\section{Patient consent for publication}

Not applicable.

\section{Competing interests}

The authors declare that they have no competing interests.

\section{References}

1. Lau W, Leung K, Leung TW, Liew CT, Chan MS, Yu SC and Li AK: A logical approach to hepatocellular carcinoma presenting with jaundice. Ann Surg 225: 281-285, 1997.

2. Uchima-Koecklin H, Balderramo D and Cárdenas A: Bile duct hepatocellular carcinoma thrombi. Gastroenterol Hepatol 35: 326-329, 2012.

3. Ikenaga N, Chijiiwa K, Otani K, Ohuchida J, Uchiyama S and Kondo K: Clinicopathologic characteristics of hepatocellular carcinoma with bile duct invasion. J Gastrointest Surg 13: 492-497, 2009.

4. Hu XG, Mao W, Hong SY, Kim BW, Xu WG and Wang HJ: Surgical treatment for hepatocellular carcinoma with bile duct invasion. Ann Surg Treat Res 90: 139-146, 2016.

5. Oba A, Takahashi S, Kato Y, Gotohda N, Kinoshita T, Shibasaki H, Ikeda M and Konishi M: Usefulness of resection for hepatocellular carcinoma with macroscopic bile duct tumor thrombus. Anticancer Res 34: 4367-4372, 2014. 
6. Xiangji L, Weifeng T, Bin Y, Chen L, Xiaoqing J, Baihe Z, Feng $S$ and Mengchao W: Surgery of hepatocellular carcinoma complicated with cancer thrombi in bile duct: Efficacy for criteria for different therapy modalities. Langenbecks Arch Surg 394: 1033-1039, 2009.

7. Yu XH, Xu LB, Liu C, Zhang R and Wang J: Clinicopathological characteristics of 20 cases of hepatocellular carcinoma with bile duct tumor thrombi. Dig Dis Sci 56: 252-259, 2011.

8. Yeh CN, Jan YY, Lee WC and Chen MF: Hepatic resection for hepatocellular carcinoma with obstructive jaundice due to biliary tumor thrombi. World J Surg 28: 471-475, 2004.

9. Ha TY, Hwang S, Moon DB, Ahn CS, Kim KH, Song GW, Jung DH, Park GC, Park HW, Park YH, et al: Long-term survival analysis of liver transplantation for hepatocellular carcinoma with bile duct tumor thrombus. Transplant Proc 46: 774-777, 2014.

10. Wang YD, Xue HZ, Jiang QF, Shen Q, Wang LC, Zhang X, $\mathrm{Lu} \mathrm{B}, \mathrm{Yu} \mathrm{M}$ and Li K: Surgical operation and re-operation for hepatocellular carcinoma with bile duct thrombosis. Chin Med J (Engl) 123: 2163-2170, 2010.

11. Shiomi M, Kamiya J, Nagino M, Uesaka K, Sano T, Hayakawa N, Kanai M, Yamamoto H and Nimura Y: Hepatocellular carcinoma with biliary tumor thrombi: Aggressive operative approach after appropriate preoperative management. Surgery 129: 692-698, 2001.

12. Qin LX, Ma ZC, Wu ZQ, Fan J, Zhou XD, Sun HC, Ye QH, Wang L and Tang ZY: Diagnosis and surgical treatments of hepatocellular carcinoma with tumor thrombosis in bile duct: Experience of 34 patients. World J Gastroenterol 10: 1397-1401, 2004.

13. Peng SY, Wang JW, Liu YB, Cai XJ, Deng GL, Xu B and Li HJ: Surgical intervention for obstructive jaundice due to biliary tumor thrombus in hepatocellular carcinoma. World J Surg 28 : 43-46, 2004

14. Yang XW, Yuan JM, Chen JY, Yang J, Gao QG, Yan XZ, Zhang BH, Feng $\mathrm{S}$ and Wu MC: The prognostic importance of jaundice in surgical resection with curative intent for gallbladder cancer. BMC Cancer 14: 652, 2014.

15. International Union Against Cancer: TNM classification of malignant tumors, 7th edition Wiley, New York, 2009.

16. Charrez B, Qiao L and Hebbard L: Hepatocellular carcinoma and non-alcoholic steatohepatitis: The state of play. World J Gastroenterol 22: 2494-2502, 2016.

17. Batsis JA, Halfdanarson TR and Pitot H: Extra-hepatic hepatocellular carcinoma presenting as obstructive jaundice. Dig Liver Dis 38: 768-771, 2006.

18. Kojiro M, Kawabata K, Kawano Y, Shirai F, Takemoto N and Nakashima T: Hepatocellular carcinoma presenting as intrabile duct tumor growth: A clinicopathologic study of 24 cases. Cancer 49: 2144-2147, 1982.

19. Llovet JM, Burroughs A and Bruix J: Hepatocellular carcinoma. Lancet 362: 1907-1917, 2003.

20. European Association for the study of the Liver, European Organisation for Research and Treatment of Cancer. EASL-EORTC clinical practice guidelines: Management of hepatocellular carcinoma. J Hepatol 56: 908-943, 2012.

21. Lee JM, Jang BK, Lee YJ, Choi WY, Choi SM, Chung WJ, Hwang JS, Kang KJ, Kim YH, Chauhan AK, et al: Survival outcomes of hepatic resection compared with transarterial chemoembolization or sorafenib for hepatocellular carcinoma with portal vein tumor thrombosis. Clin Mol Hepatol 22: 160-167, 2016.
22. Minagawa $\mathbf{M}$ and Makuuchi M: Treatment of hepatocellular carcinoma accompanied by portal vein tumor thrombus. World J Gastroenterol 12: 7561-7567, 2006.

23. Tan WF, Qiu ZQ, Yu Y, Ran RZ, Yi B, Lau WY, Liu C, Qiu YH, Feng FL, Wang JH, et al: Sorafenb extends the survival time of patients with multiple recurrences of hepatocellular carcinoma after liver transplantation. Acta Pharmacol Sin 31: 1643-1648, 2010.

24. Pitt HA, Gomes AS, Lois JF, Mann LL, Deutsch LS and Longmire WP Jr: Does preoperative percutaneous biliary drainage reduce operative risk or increase hospital cost? Ann Surg 201: 545-553, 1985.

25. Yamamoto S, Hasegawa K, Inoue Y, Shindoh J, Aoki T, Sakamoto Y, Sugawara Y, Makuuchi M and Kokudo N: Bile duct preserving surgery for hepatocellular carcinoma with bile duct tumor thrombus. Ann Surg 261: e123-e125, 2015.

26. Sewnath ME, Karsten TM, Prins MH, Rauws EJ, Obertop H and Gouma DJ: A meta-analysis on the efficacy of preoperative biliary drainage for the tumors causing obstructive jaundice. Ann Surg 236: 17-27, 2002

27. Agarwal AK, Mandal S, Singh S, Bhojwani R, Sakhuja P and Uppal R: Biliary obstruction in gall bladder cancer is not sine qua non of inoperability. Ann Surg Oncol 14: 2831-2837, 2007.

28. Choi J, Ryu JK, Lee SH, Ahn DW, Hwang JH, Kim YT, Yoon YB and Han JK: Biliary drainage for obstructive jaundice caused by unresectable hepatocellular carcinoma: The endoscopic versus percutaneous approach. Hepatobiliary Pancreat Dis Int 11: 636-642, 2012

29. Cho HC, Lee JK, Lee KH, Lee KT, Paik S, Choo SW, Do YS and Choo IW: Are endoscopic or percutaneous biliary drainage effective for obstructive jaundice caused by hepatocellular carcinoma? Eur J Gastroenterol Hepatol 23: 224-231, 2011.

30. Noda T, Nagano H, Tomimaru Y, Murakami M, Wada H, Kobayashi S, Marubashi S, Eguchi H, Takeda Y, Tanemura M, et al: Prognosis of hepatocellular carcinoma with biliary tumor thrombi after liver surgery. Surgery 149: 371-377, 2011.

31. Chen C, Chen PJ, Yang PM, Huang GT, Lai MY, Tsang YM and Chen DS: Clinical and microbiological features of liver abscess after transarterial embolization for hepatocellular carcinoma. Am J Gastroenterol 92: 2257-2259, 1997.

32. de Baère T, Risse O, Kuoch V, Dromain C, Sengel C, Smayra T, Gamal El Din M, Letoublon C and Elias D: Adverse events during radiofrequency treatment of 582 hapatic tumors. AJR Am J Roentgenol 181: 695-700, 2003.

33. A new prognostic system for hepatocellular carcinoma: A retrospective study of 435 patients: The Cancer of the Liver Italian Program (CLIP) investigators. Hepatology 28: 751-755, 1998.

34. Chung H, Kudo M, Takahashi S, Hagiwara S, Sakaguchi Y, Inoue T, Minami Y, Ueshima K, Fukunaga T and Matsunaga T: Comparison of three current staging systems for hepatocellular carcinoma: Japan integrated staging score, new Barcelona Clinic Liver Cancer staging classification and Tokyo score. J Gastroenterol Hepatol 23: 445-452, 2008.

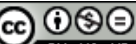

This work is licensed under a Creative Commons Attribution-NonCommercial-NoDerivatives 4.0 International (CC BY-NC-ND 4.0) License. 